\title{
Sodium-Polystyrene Sulfonate-Induced Colitis
}

\author{
Francisco Souza dos Santos $^{a}$ Gabriel Peixoto Aver ${ }^{a}$ Thais Vieira Paim ${ }^{a}$ \\ Floriano Riva ${ }^{b}$ Eduardo Brambillac, d Jonathan Solderac, e \\ a School of Medicine, Universidade de Caxias do Sul, Caxias do Sul, Brazil; ${ }^{b}$ Centro de Patologia Médica (CPM), \\ Caxias do Sul, Brazil; ' Clinical Gastroenterology, School of Medicine, Universidade de Caxias do Sul, Caxias do Sul,

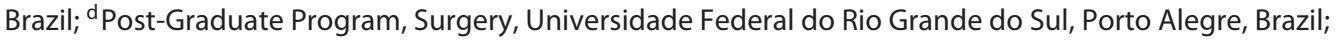 \\ ePost-Graduate Program, Pathology, Universidade Federal de Ciências da Saúde de Porto Alegre, Porto Alegre, Brazil
}

\section{Keywords}

Sodium polystyrene sulfonate $\cdot$ Diarrhea $\cdot$ Colitis

\section{Colite secundária à poliestirenossulfonato de sódio}

\section{Palavras Chave}

Poliestirenossulfonato de sódio · Diarreia · Colite

A 77-year-old woman was admitted to the hospital because of abdominal distension and vomiting. Laboratory workup showed acute kidney injury with serum creatinine of $3.5 \mathrm{mg} / \mathrm{dL}$ and potassium of $5.7 \mathrm{mmol} / \mathrm{L}$. Intravenous hydration, antibiotics, and symptomatic medication were started. Sodium polystyrene sulfonate (SPS) $15 \mathrm{~g}$ twice daily was used to treat hyperkalemia. After $48 \mathrm{~h}$, serum potassium decreased to $3.7 \mathrm{mmol} / \mathrm{L}$, and creatinine to $1.8 \mathrm{md} / \mathrm{dL}$. On day 4 of admission she developed watery diarrhea, initially managed with probiotics and dietary modification. Infectious workup was negative for Clostridioides difficile, parasites, and Cytomegalovirus.
Colonoscopy revealed edema, enanthema, and erosion into the sigmoid colon (Fig. 1). Biopsy showed typical fish scale-like SPS crystals (Fig. 2). SPS administration was discontinued, and the patient's condition progressively improved until resolution.

The use of SPS (or Kayexalate) to treat hyperkalemia dates back to the 1960s. Common side effects include constipation, bloating, nausea, and vomiting. Patients with previous kidney damage account for more than $70 \%$ of those who develop side effects, which often occur after 2 days of SPS administration. SPS-induced colitis is rarely detected by colonoscopy. Biopsy shows necrosis, ulceration, and SPS crystal deposition in more than $90 \%$ of samples. These features can distinguish SPS-induced necrosis from ischemic necrosis. A definitive diagnosis requires excluding conditions that mimic SPS-induced colitis, such as neoplasms, inflammatory bowel disease, microscopic colitis, C. difficile infection, and infectious colitis.

The first cases of SPS-associated ulceration and colonic necrosis were reported by Lillemoe et al. [1] in 1987. In 2013, a systematic review identified 58 cases of serious adverse reactions to SPS use. Colonic necrosis

\section{(c) 2021 Sociedade Portuguesa de Gastrenterologia.} Published by S. Karger AG, Basel

This is an Open Access article licensed under the Creative Commons Attribution-NonCommercial-4.0 International License (CC BY-NC) (http://www.karger.com/Services/OpenAccessLicense), applicable to the online version of the article only. Usage and distribution for commercial purposes requires written permission.
Correspondence to:

Jonathan Soldera, jonathansoldera@ gmail.com 
Fig. 1. Sigmoid colon, colonoscopy. Colitis: edema, enanthema, and mucosal erosion.

Fig. 2. Sigmoid colon, biopsy. a Mucosal injury with intraepithelial neutrophils (HE $\times 200$ ). b Polystyrene crystals displaying a fish-scale appearance $(\mathrm{HE} \times 600)$.
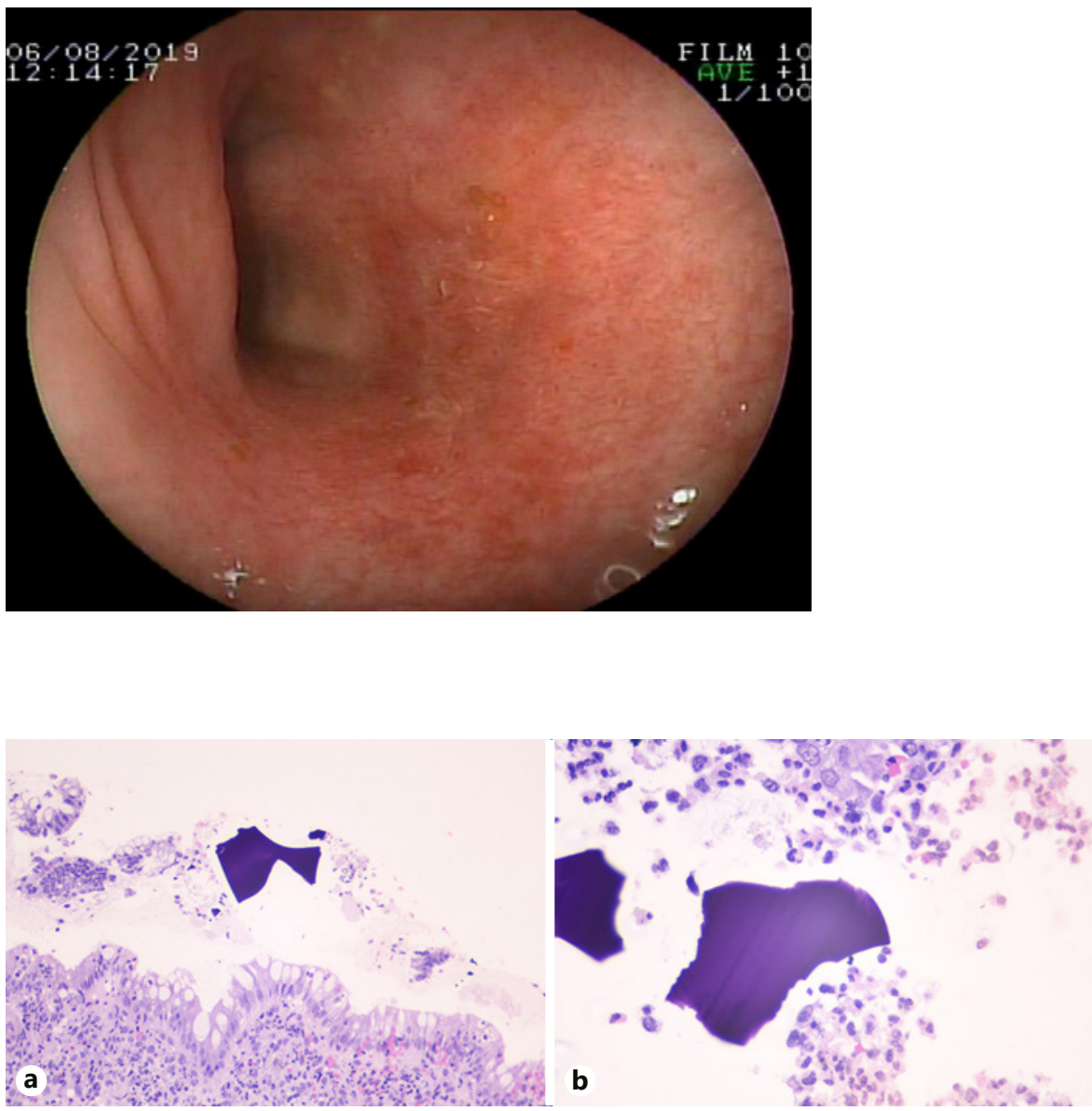

was the most severe complication, resulting in a mortality rate of 33\% [2]. Nevertheless, a recent systematic review and meta-analysis showed that, although there was a statistically significantly increased risk for the composite outcome of severe gastrointestinal side effects based on 2 studies, there was no definite association of SPS use with intestinal necrosis [3]. In rats, SPS enema was associated with colonic necrosis and a high mortality rate [4]. Because intestinal necrosis is a life-threatening condition, caution should be exercised before prescribing SPS in patients at risk for complications [5]. Currently, there is no specific treatment for SPS-induced colitis, and medication withdrawal often results in symptom improvement.

In conclusion, SPS-induced colitis is a rare cause of diarrhea in the hospital setting. It should be suspected especially in patients with previous kidney damage who have received treatment for hyperkalemia.

\section{Statement of Ethics}

The family of the deceased patient verbally agreed to the reporting of the case.

\section{Conflict of Interest Statement}

The authors have no conflicts of interest to declare.

\section{Funding Sources}

None.

\section{Author Contributions}

All authors equally contributed to writing and reviewing the paper. 


\section{References}

1 Lillemoe KD, Romolo JL, Hamilton SR, Pennington LR, Burdick JF, Williams GM. Intestinal necrosis due to sodium polystyrene (Kayexalate) in sorbitol enemas: clinical and experimental support for the hypothesis. Surgery. 1987 Mar;101(3):267-72.

2 Harel Z, Harel S, Shah PS, Wald R, Perl J, Bell CM. Gastrointestinal adverse events with sodium polystyrene sulfonate (Kayexalate) use: a systematic review. Am J Med. 2013 Mar;126(3):264.e9-24.

3 Holleck JL, Roberts AE, Marhoffer EA, Grimshaw AA, Gunderson CG. Risk of intestinal necrosis with sodium polystyrene sulfonate: a systematic review and meta-analysis. J Hosp Med. 2021 Aug;16(8):489-94.

4 Ayoub I, Oh MS, Gupta R, McFarlane M, Babinska A, Salifu MO. Colon necrosis due to sodium polystyrene sulfonate with and without sorbitol: an experimental study in rats. PLoS One. 2015 Sep;10(9): e0137636.

5 Almulhim AS, Hall E, Mershid Al Rehaili B, Almulhim AS. Sodium polystyrene sulfonate induced intestinal necrosis; a case report. Saudi Pharm J. 2018 Sep;26(6):771-4. 